\title{
Technology and performances of silicon oxynitride waveguides for optomechanical sensors fabricated by plasma-enhanced chemical vapour deposition
}

\author{
A. Sabac \\ C. Gorecki \\ christophe.gorecki@femto-st.fr
}

M. Jozwik

L. Nieradko

C. Meunier

K. Gut

\author{
Département d'Optique, FEMTO-ST (UMR 6174 CNRS), 16 route de Gray, 25030 Besançon cedex, \\ France \\ Département d'Optique, FEMTO-ST (UMR 6174 CNRS), 16 route de Gray, 25030 Besançon cedex, \\ France \\ Département d'Optique, FEMTO-ST (UMR 6174 CNRS), 16 route de Gray, 25030 Besançon cedex, \\ France \\ Département d'Optique, FEMTO-ST (UMR 6174 CNRS), 16 route de Gray, 25030 Besançon cedex, \\ France \\ Département CREST, FEMTO-ST (UMR 6174 CNRS), BP 71427, Montbéliard cedex 25211, France
}

The technology and performance of micromachined channel waveguides, based on plasma-enhanced chemical vapour deposition (PECVD) of silicon oxynitride thin films, are presented. The deposition parameters of PECVD are studied in connection with their optical, mechanical and chemical properties. The design of the waveguide is optimised for single mode operation, low loss propagation and high efficiency of coupling to single mode optical fibers. This technology is applied to fabricate the pigtailed Mach-Zehnder interferometers, where the coupling from the optical fiber to the waveguide is based on U-groove etch, supporting fibers in the same substrate as the waveguide substrate. [DOI: 10.2971/jeos.2007.07026]

Keywords: integrated optics, MEMS, channel waveguide, optomechanical sensor

\section{INTRODUCTION}

During the last decade many novel micro-opto-electomechanical systems (MOEMS) including optical waveguides on silicon substrate have been developed: modulators, switches, micro platforms for integrated optics and optically driven actuators. The rapidly growing market of integrated optical sensors requires photonic components with everincreased functionality that can be fabricated reliably at low cost. Planar waveguides, when integrated with micromechanically deformable structures and linked by optical fibers, may serve as sensors to detect a physical parameter of mechanical deformation [1, 2]. Structurally active elements are typically high aspect ratio components such as suspended beams or membranes. Thus, many physical parameters (temperature, pressure, force, acceleration) can be converted to a displacement or strain. The action of this physical parameter on the waveguide read-out produces a phase or intensity modulation and thus the sensing function may be performed. The first category can use movable microstructures that interact with a guided wave through evanescent coupling or by affecting the waveguide transmission [3]. Phase-modulated sensors are often based on a Mach-Zehnder interferometry (MZI) [4, 5]. In this category, the most successful application of micromachined MZIs is in the area of pressure sensors, where one of optical branches of MZI crosses a deformable membrane $[6,7]$.
A wide variety of deposition techniques for silicon-based optical waveguides has beem developed including: chemical vapour deposition [8, 9] (CVD) and flame hydrolysis deposition [10] (FHD). Most published work refers to waveguide structures that are based on the deposition silica $\left(\mathrm{SiO}_{2}\right)$ for the cladding layers and doped silica for the core layer [11], and silicon nitride $\left(\mathrm{Si}_{3} \mathrm{~N}_{4}\right)$ or silicon oxynitride $\left(\mathrm{SiO}_{\mathrm{x}} \mathrm{N}_{\mathrm{y}}\right)$ for the core layer $[12,13]$.

Since $\mathrm{SiO}_{\mathrm{x}} \mathrm{N}_{\mathrm{y}}$ waveguides permit low attenuation of light and well adjustable refractive index, this material is suitable for matching to single-mode fibres, due to the possibility to tailor the mode-field profile of such waveguides to that of silica-based optical fibers. A suitable deposition process is the plasma-enhanced chemical vapour deposition (PECVD). PECVD operating at relatively high deposition rate and low temperature of deposition is compatible with the well-established microelectronic processing [14]. Because the quality of $\mathrm{SiO}_{\mathrm{x}} \mathrm{N}_{\mathrm{y}}$ films depends strongly on PECVD parameters, we propose to improve the performances of deposited thin films by establishing the relationship between the optical performances, chemistry, and growth parameters of $\mathrm{SiO}_{\mathrm{x}} \mathrm{N}_{\mathrm{y}}$ thin films. We report then the influence of these properties on the mechanical behaviour of $\mathrm{SiO}_{\mathrm{x}} \mathrm{N}_{\mathrm{y}}$ films. A fabrication procedure is proposed for $\mathrm{SiO}_{x} \mathrm{~N}_{y}$ buried channel waveguides, exhibiting low propagation loss, well-controlled refractive in- 
dex and low-internal stress. The design of such waveguide is optimised to be applied as a read-out of mechanical parameters in the MZI architecture, where the measuring branch is crossing the MEMS actuator and the rigid reference branch is outside of the actuator $[15,16]$. To obtain the optimal design 3D Beam Propagation Method (BPM) and Finite Element Method (FEM) have been performed, determining the modal analysis as well as the coupling efficiency and helping to define the consequences of elastooptic effects on MZI read-out. Finally, the MZI is monolithically integrated on top of a membrane, including a micromachined fiber-to-waveguide coupling platform. The resulting optoelectronic device is experimentally tested.

\section{PECVD DEPOSITION OF SIO $\mathrm{N}_{\mathrm{Y}}$ FILMS}

Monolithic integration of channel waveguides with moving parts of MEMS requires layers with well established compromise between optical, mechanical and chemical properties. Main requirements are good control of the refractive in$\operatorname{dex}\left(\sim 10^{-3}\right)$, low attenuation, reproducibility and low stress. It has been demonstrated that PECVD offers a good control of the optical, mechanical and chemical properties of $\mathrm{SiO}_{x} \mathrm{~N}_{y}$ films [17]-[21]. Those properties are strongly dependent on the deposition parameters such as the temperature of substrate, precursor gas flow ratio, RF frequency, RF power and total pressure.

$\mathrm{SiO}_{\mathrm{x}} \mathrm{N}_{\mathrm{y}}$ films are fabricated by a parallel plate PECVD radial flow reactor (PLASSYS MPC400). Three processing gasses: silane $\left(\mathrm{SiH}_{4}\right)$, ammonia $\left(\mathrm{NH}_{3}\right)$ and nitrous oxide $\left(\mathrm{N}_{2} \mathrm{O}\right)$ are supplied from individual flow control systems inside the reactor chamber. The substrate temperature during the deposition was $350^{\circ} \mathrm{C}$, the RF power is fixed at $0.37 \mathrm{~W} / \mathrm{cm}^{2}$, RF frequency at $150 \mathrm{kHz}$ and the pressure at $0.14 \mathrm{mbar}$ for a total gas flow of $150 \mathrm{sccm}$ (sccm is the flow unit defined as "standard $\mathrm{cm}^{3}$ per minute"). Under these general conditions [22] all $\mathrm{SiO}_{\mathrm{x}} \mathrm{N}_{\mathrm{y}}$ samples were prepared varying only the gas flow ratio of $\mathrm{N}_{2} \mathrm{O}$ and $\mathrm{NH}_{3}$. When the ratio $\mathrm{R}_{1}=\mathrm{N}_{2} \mathrm{O} /\left(\mathrm{N}_{2} \mathrm{O}+\mathrm{NH}_{3}\right)$ is varying from 0 to 1 , then the refractive index of the $\mathrm{SiO}_{\mathrm{x}} \mathrm{N}_{\mathrm{y}}$ is adjusted from 1.815 to 1.469. Letters E01-E06 denotes $\mathrm{SiO}_{x} \mathrm{~N}_{y}$ samples for which the deposition parameters are listed in Table 1 .

\begin{tabular}{|c|c|c|c|c|}
\hline Sample & $\mathrm{R}_{1}$ & $\mathrm{~N}_{2} 0(\mathrm{sccm})$ & $\mathrm{SiH}_{4}(\mathrm{sccm})$ & $\mathrm{NH}_{3}(\mathrm{sccm})$ \\
\hline E01 & 1 & 143 & 7 & 0 \\
\hline E02 & 0.88 & 126 & 7 & 17 \\
\hline E03 & 0.60 & 86 & 7 & 57 \\
\hline E04 & 0.32 & 46 & 7 & 97 \\
\hline E05 & 0.11 & 17 & 7 & 126 \\
\hline E06 & 0 & 0 & 7 & 143 \\
\hline
\end{tabular}

TABLE 1 Gas flows of PECVD-deposited samples.

The refractive indices were measured by ellipsometry at a wavelength of $632.8 \mathrm{~nm}$. The relationship between the refractive index of $\mathrm{SiO}_{\mathrm{x}} \mathrm{N}_{\mathrm{y}}$ and the gas flow ratio is shown in Figure 1.

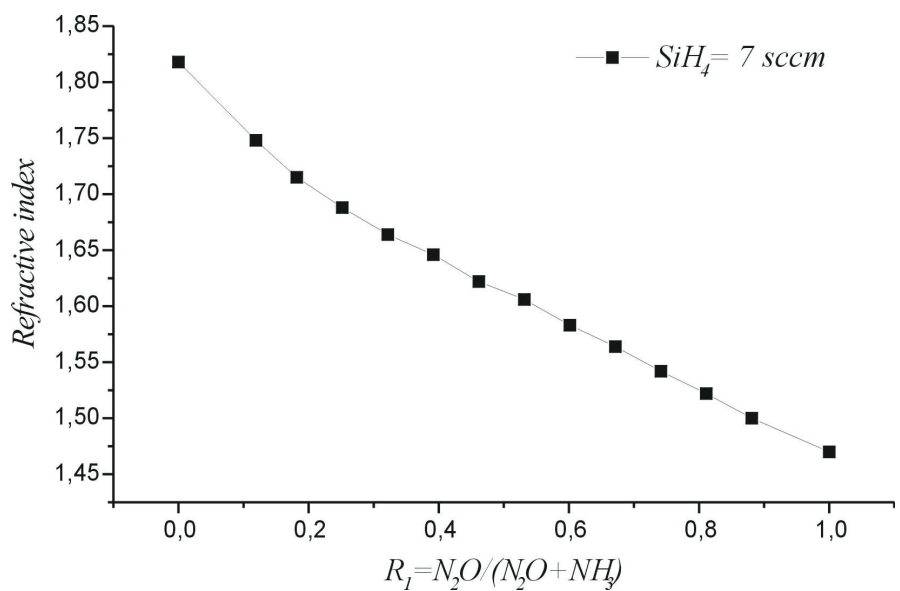

FIG. 1 Refractive index of $\mathrm{SiO}_{x} \mathrm{~N}_{y}$ layers vs. gas flow ratio $\mathrm{R}_{1}$.

\section{STUDY OF PHYSICAL AND MECHANICAL PARAMETERS OF $\mathrm{SIO}_{\mathrm{X}} \mathrm{N}_{\mathrm{Y}}$ THIN FILMS}

\subsection{Physical parameters of $\mathrm{SiO}_{\mathrm{x}} \mathrm{N}_{\mathrm{y}}$ films}

We analysed the samples E01-06 [23] within a Van der Graaff accelerator by using the RBS detector (Rutherford Backscattering Spectroscopy) detector and ERDA (Elastic Recoil Detection Analysis). RBS measurements were used to obtain the composition and thickness of $\mathrm{SiO}_{\mathrm{x}} \mathrm{N}_{\mathrm{y}}$, as shown in Figure 2. This illustrates ERDA spectra for samples E06, the sample an-

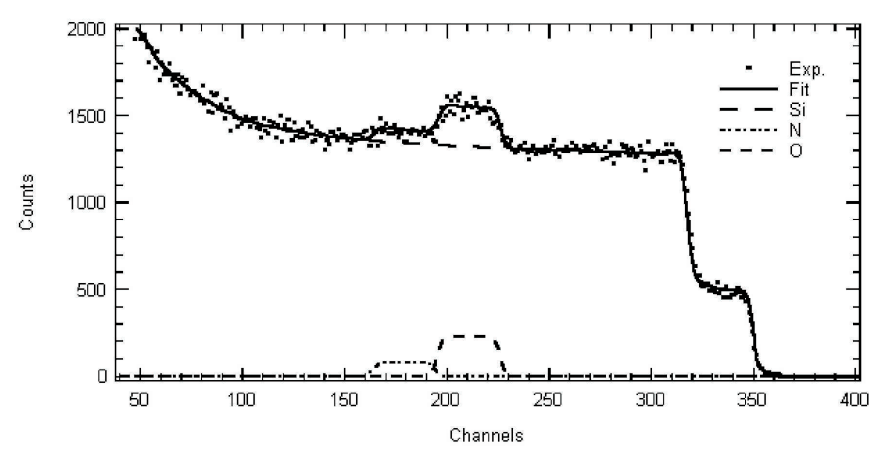

FIG. 2 RBS spectrum for the sample Eo6.

gle being at $76^{\circ}$ and detector angle at $20^{\circ}$, as shown in Figure 3. ERDA was used to obtain the depth profile for hydrogen. The experimental results are given in number of counts collected per channel data; channels being calibrated in energy units (keV).We used an XRR system (X-Ray Reflectivity) to determine electronic densities of $\mathrm{SiO}_{\mathrm{x}} \mathrm{N}_{\mathrm{y}}$ films. All samples have a homogeneous layer composition within the depth resolution of RBS and XRR of about $5 \mathrm{~nm}$. Experimental data are summarized in Table 2.

Figure 4 illustrates the atomic percent (at \%) of silicon, nitrogen, oxygen and hydrogen as a function of refractive indices, giving information on mass density of deposited films. Atomic concentration (atom $/ \mathrm{cm}^{2}$ ) and film volume was deduced from the film thickness, while the density $\left(\mathrm{g} / \mathrm{cm}^{3}\right)$ was determined by weighting the substrate before and after deposition of film. 


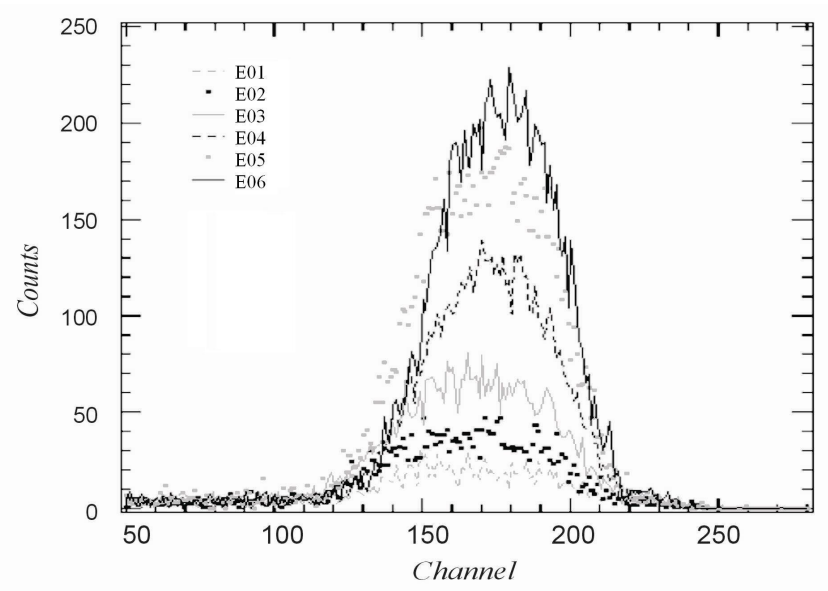

FIG. 3 ERDA spectra fore sample series E01-E06.

According to the data of Figure 4, the amount of incorporated nitrogen increase with increasing refractive index $(0 \%-$ $52 \%)$, while the concentration of oxygen decreases with increasing of refractive index $(65 \%-0 \%)$. The silicon content is

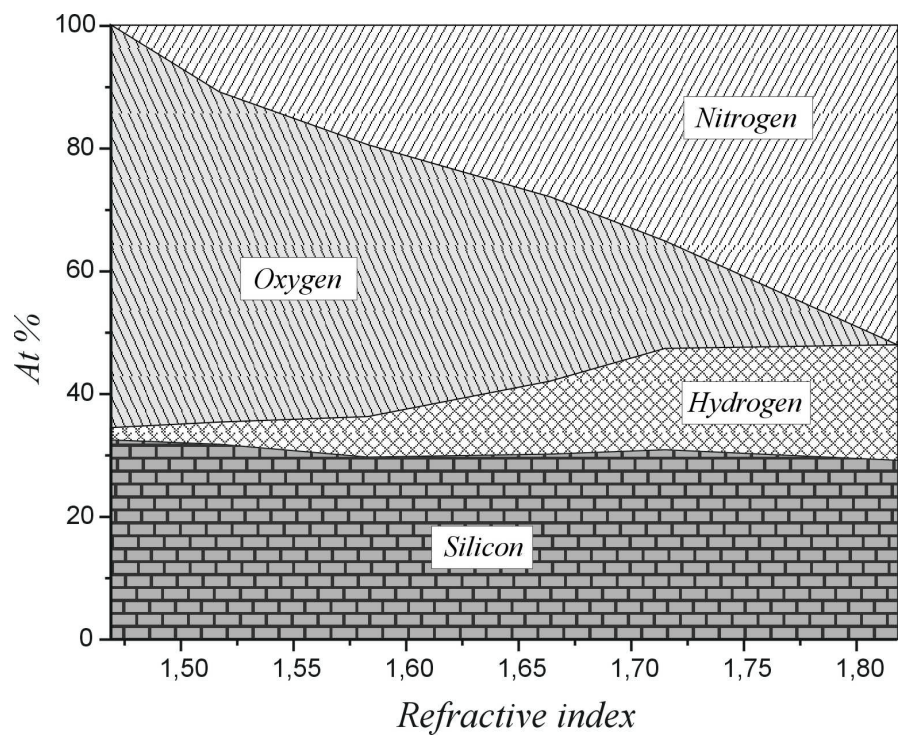

FIG. 4 Atomic concentrations of silicon, nitrogen, hydrogen and oxygen vs. the refractive index of $\mathrm{SiO}_{x} \mathrm{~N}_{y}$ films.

relatively independent from the refractive index $(29 \%-32 \%)$. Hydrogen has particularly important effects on the optomechanical properties of deposited films: his total content is a sum of $\mathrm{N}-\mathrm{H}$ and $\mathrm{Si}-\mathrm{H}$ bond concentrations. In the oxide like samples just $\mathrm{Si}-\mathrm{H}$ bonds are observed, whereas in nitride like samples both $\mathrm{Si}-\mathrm{H}$ and $\mathrm{N}-\mathrm{H}$ bonds are present. In the nitride like samples the content of $\mathrm{N}-\mathrm{H}$ bonds increases and the amount of oxide like samples decreases when $\mathrm{N}_{2} \mathrm{O}$ flow is increased. Because the amount of $\mathrm{N}-\mathrm{H}$ bonds increases significantly with the increase of refractive index (whereas the concentration of $\mathrm{Si}-\mathrm{H}$ bonds seems to be stable), hydrogen atomic percentage increases rapidly with increasing refractive index (2\%-18.8\%). The experimental data reveal a relatively linear increase in density with increasing refractive index, accompanied by a jump for the sample E02 ( $n=1.517)$. The oxide-like film (sample E01, $n=1.469$ ) has a density slightly upper than fused silica with $2.29 \mathrm{~g} / \mathrm{cm}^{3}$. The nitride-like film (sample E06, $n=1.815$ ) has the higher density with $2.70 \mathrm{~g} / \mathrm{cm}^{3}$.

\begin{tabular}{|c|c|c|c|c|c|}
\hline Sample & $\rho\left(\mathrm{g} / \mathrm{cm}^{3}\right)$ & $\mathrm{Si}(\mathrm{at} \%)$ & $\mathrm{O}(\mathrm{at} \%)$ & $\mathrm{N}($ at $\%)$ & $\mathrm{H}(\mathrm{at} \%)$ \\
\hline E01 & 2,29 & 32,4 & 65,6 & 0 & 2,0 \\
\hline E02 & 2,44 & 31,7 & 53,8 & 10,9 & 3,6 \\
\hline E03 & 2,36 & 29,6 & 44,3 & 19,5 & 6,6 \\
\hline E04 & 2,43 & 30,1 & 30,0 & 28,0 & 11,9 \\
\hline E05 & 2,52 & 30,8 & 17,5 & 35,2 & 16,5 \\
\hline E06 & 2,71 & 29,1 & 0 & 52,1 & 18,8 \\
\hline
\end{tabular}

TABLE 2 Density and atomic concentration of samples E01-6.

\subsection{Mechanical properties of $\mathrm{SiO}_{\mathrm{x}} \mathrm{N}_{\mathrm{y}}$ films}

This study of material properties is completed by a previous work [19, 23], where the micromechanical properties of PECVD deposited films have been measured by "point-wise" deflection method. Figure 5 shows the distribution of residual stress as a function of the refractive index of $\mathrm{SiO}_{\mathrm{x}} \mathrm{N}_{\mathrm{y}}$ films. Upon increasing the refractive index from 1.49 to 1.58 the

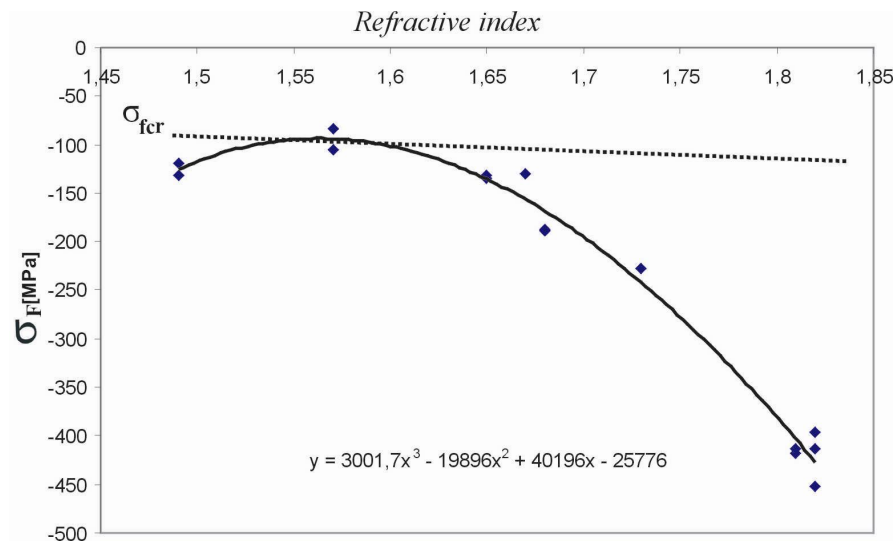

FIG. 5 Distribution of residual stress vs. the refractive index of $\mathrm{SiO}_{x} \mathrm{~N}_{\mathrm{y}}$ films.

stress is minimal for 1.58 with the magnitude of $-100 \mathrm{MPa}$ and then becomes less compressive. We have observed that around this value of refractive index, the film density is lower. Thus, $\mathrm{SiO}_{x} \mathrm{~N}_{y}$ layers with refractive index in the range of $1.47-1.65$ are the most suitable for optical waveguides, demonstrating a relatively low compressive stress (from -150 to $-90 \mathrm{MPa})$. For nitride-like films $(n=1.81)$ the stress changes to more compressive with the increase of refractive index. Here the stress magnitude is around $-400 \mathrm{MPa}$ with higher density.

On the other hand, $\mathrm{H}$ content of the layers increases with the refractive index from $2 \%$ to $18.8 \%$. Excessive hydrogen content causes optical losses in the infrared region mainly due to the $\mathrm{Si}-\mathrm{H}$ and $\mathrm{N}-\mathrm{H}$ bond absorption [24]. Other disadvantage is that in case of annealing in temperatures over $600^{\circ} \mathrm{C}$, the refractive index changes dramatically due to $\mathrm{H}$ desorbtion and layer cracks may appear. Thus, for thin films with refractive index in the range $1.47-1.55$ the $\mathrm{H}$ content is less than $5 \%$. 


\section{DESIGN OF CHANNEL WAVEGUIDE FOR INTEGRATED MACH-ZEHNDER INTERFEROMETRY}

The optical design was performed for waveguides operating at the wavelength of $670 \mathrm{~nm}$ and presenting single-mode operation with moderate propagation loss through bends with radii of curvature around $30-40 \mathrm{~mm}$. The coupling efficiency around $60 \%$ is expected. The chosen configuration is the buried $\mathrm{SiO}_{\mathrm{x}} \mathrm{N}_{\mathrm{y}}$ waveguide, as shown in Figure 6. It con-

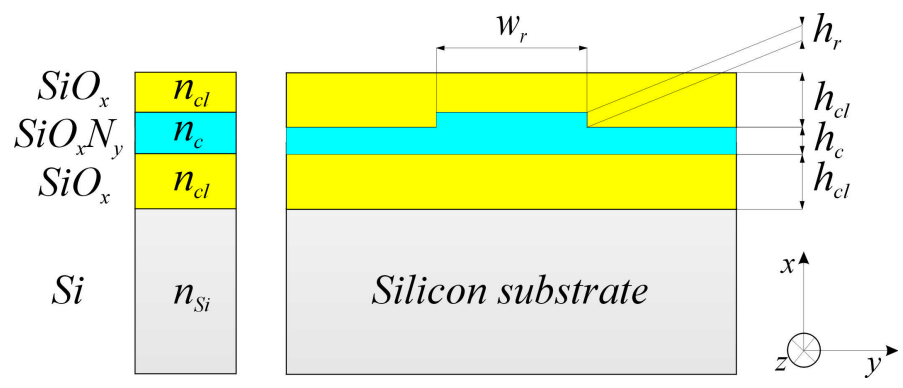

FIG. 6 Cross-section of $\mathrm{SiO}_{\mathrm{x}} \mathrm{N}_{\mathrm{y}}$ buried waveguide.

sists of $\mathrm{SiO}_{2}-\mathrm{SiO}_{\mathrm{x}} \mathrm{N}_{\mathrm{y}}-\mathrm{SiO}_{2}$ sandwich with a rib structure embedded in top cladding. Optimisation of this architecture has been carried out, making a compromise between the properties of PECVD $\mathrm{SiO}_{\mathrm{x}} \mathrm{N}_{\mathrm{y}}$ layers, technological limitations, single mode operation and optical loss.

\subsection{Choice of the refractive index and single mode operation}

The properties of the deposited layers depend strongly on the deposition conditions. In Section 3, we established the relationship between the mechanical stress, the hydrogen content, the uniformity and the refractive index of the $\mathrm{SiO}_{\mathrm{x}} \mathrm{N}_{\mathrm{y}}$ layers. For refractive indices between 1.47 and 1.65, the residual stress is lower than $-150 \mathrm{MPa}$ and hydrogen contamination does not exceed 12\% (see Figure 5). Under those conditions, the refractive index was set to 1.53 for the core layer and to 1.47 for the cladding layer, respectively. The uniformity of the refractive index is excellent for both values $\left(3 \times 10^{-3}\right)$ and the thickness uniformity is less than $2 \%$ for the core layer, as shown in Figure 7.

The single mode operation of the waveguide with those selected thin films will depend from parameters of the core medium: core thickness, rib height and rib waist. The rib waist is fixed to $4 \mu \mathrm{m}$ which is a reasonable limit for good reproducibility of the contact lithography process. Under those conditions and for a fixed thickness of core layer, the single mode propagation depends only from the rib height. When the core thickness and the rib height exceed a certain value, the waveguide becomes multimode. The single mode propagation condition was calculated using the effective index method. Figure 8 shows the single mode condition defined as the maximum rib height for a given range of core thickness.

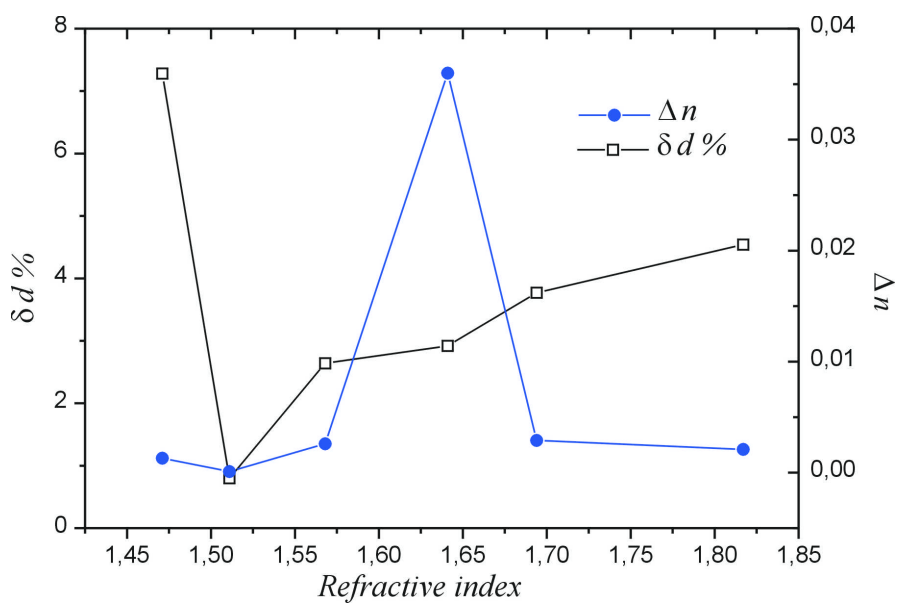

FIC. 7 In-homogeneity of refractive index and in-homogeneity of thickness vs. the value of refractive index of $\mathrm{SiO}_{\mathrm{x}} \mathrm{N}_{\mathrm{y}}$ layers.

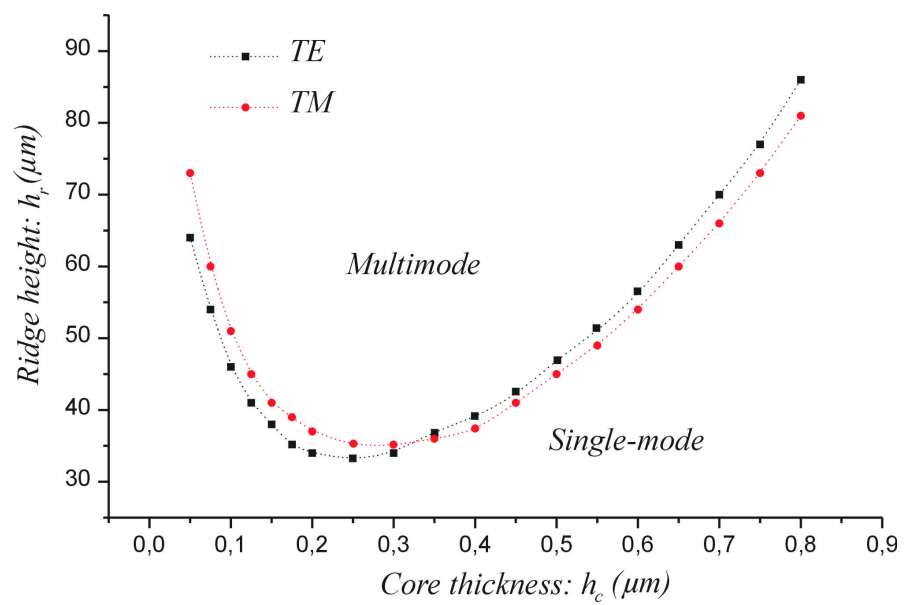

FIG. 8 Limits of single-mode and multi-mode behaviours: dependency from the geometrical parameter of the core layer.

\subsection{Coupling efficiency and propagation losses}

Fiber-to-waveguide coupling efficiency is given by the field overlap integral:

$$
\eta=\frac{\iint E_{w} E_{f}^{*} d x d y \iint E_{f} E_{w}^{*} d x d y}{\iint E_{w} E_{w}^{*} d x d y \iint E_{f} E_{f}^{*} d x d y}
$$

where $E_{f}$ and $E_{w}$ are respectively the mode fields for the fiber and waveguide. $E_{f}$ and $E_{w}$ are calculated using MGFD method from the commercially available mode solver (SELENE, interface of software Olympios from C2V). For calculations, we used a standard single mode optical fiber available from the company SEDI. Figure 9 illustrates the influence of rib height and core thickness on the overlap.

To obtain an overlap $\eta$ over $50 \%$ between the fundamental mode of the fiber and the fundamental mode of waveguide, the core thickness has been set at $200 \mathrm{~nm}$. In this case, the rib height should not exceed $28 \mathrm{~nm}$ for the single mode waveguides. The precision of etch with buffered HF solution (BHF) is estimated to $\pm 1.5 \mathrm{~nm}$. To ensure single mode propagation, $h_{r}$ was set to $20 \mathrm{~nm}$. Under those conditions, we obtained a theoretical overlap $\eta=64 \%$. 


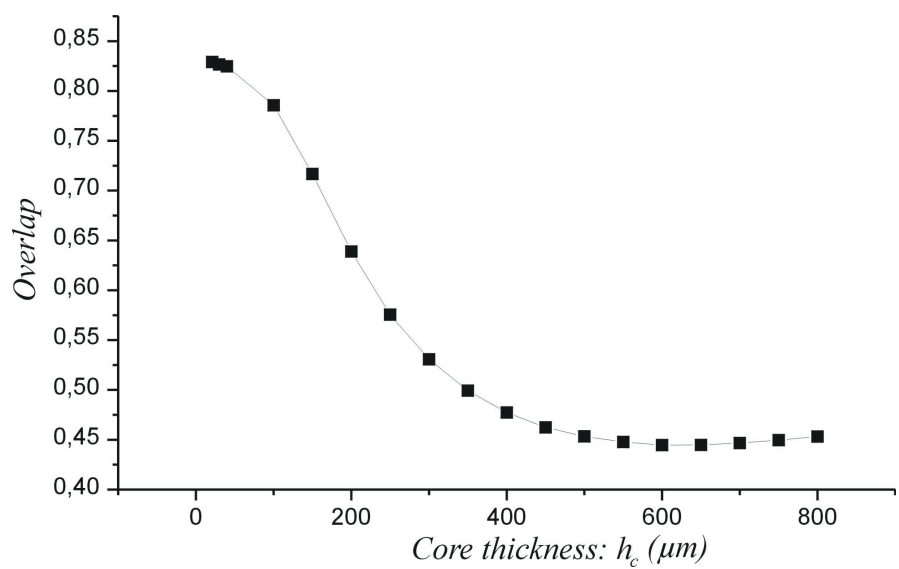

FIG. 9 Overlap vs. the core thickness.

Three different phenomena contribute to generate waveguide losses: absorption, radiation and scattering. The design is carried out with respect of attenuation caused by the silicon substrate and the radiation loss caused by the S-bends of the MZI.

Using the software Olympios, we estimated the optical attenuation caused by interaction between the guided mode and the silicon substrate [22] in case of straight waveguides. Figure 10 shows the evolution of optical loss as a function of the thickness of bottom cladding for both TE polarisation and TM polarisation. When the thickness of cladding layer attains $3 \mu \mathrm{m}$,

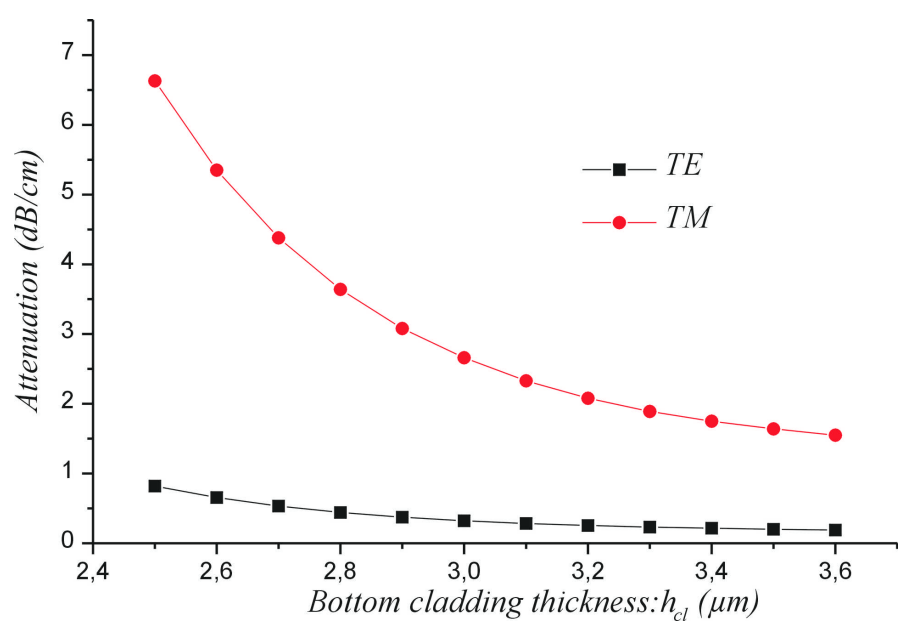

FIG. 10 Optical attenuation vs. the thickness of bottom cladding.

then the optical attenuation riches $0.32 \mathrm{~dB} / \mathrm{cm}$ for TE polarisation and $2.66 \mathrm{~dB} / \mathrm{cm}$ for $\mathrm{TM}$ polarisation, respectively.

All those data, concerning the characteristics of buried $\mathrm{SiO}_{x} \mathrm{~N}_{y}$ waveguide, are useful for the optimal choice of geometrical features of MZI architecture. To reach the distance of $2.2 \mathrm{~mm}$ between both arms of the interferometer, the BPM (Beam Propagation Method) simulation indicates a total length of $40 \mathrm{~mm}$ of MZI. The angle of Y-junction is $1^{\circ}$ and the radius of curvature of S-bends is $40 \mathrm{~mm}$, presenting low radiation loss (see Figure 11).

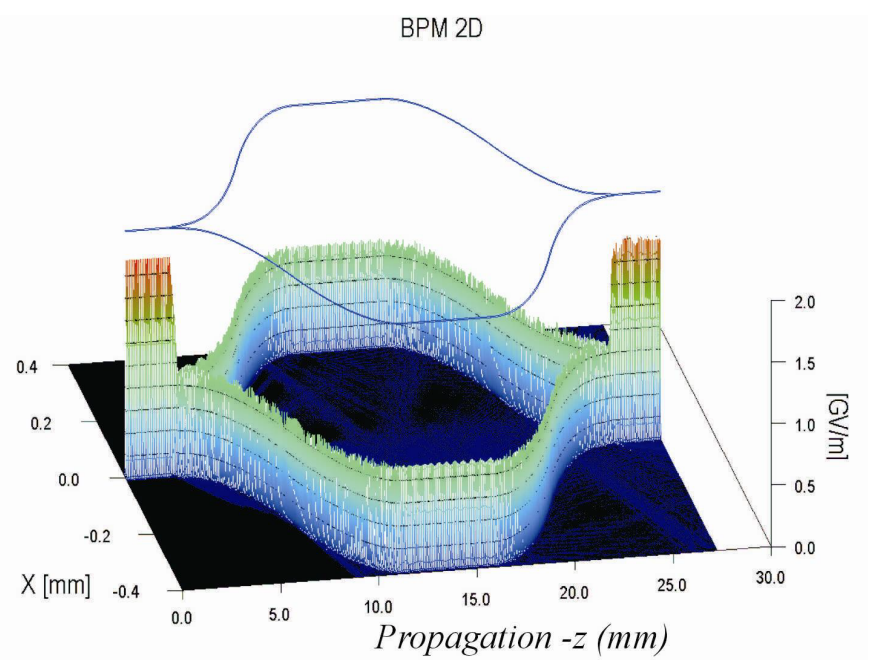

FIG. 11 BPM simulations of light propagation along the MZI.

\section{FABRICATION AND CHARACTERIZATION OF $\mathrm{SIO}_{\mathrm{X}} \mathrm{N}_{\mathrm{Y}}$ BURIED WAVEGUIDE}

\subsection{Fabrication of waveguide and evaluation of optical loss}

The fabrication of buried waveguide starts by PECVDdeposition of $3 \mu \mathrm{m}$ thick bottom cladding on top of a double side polished silicon substrate $(<100>$ oriented). This is a $\mathrm{SiO}_{2}$ layer with the refractive index at 1.47 . Then, $220 \mathrm{~nm}$ thick film of $\mathrm{SiO}_{x} \mathrm{~N}_{y}$ is deposited, playing the role of core layer with the refractive index of 1.53 . A $4 \mu \mathrm{m}$ wide rib was patterned by photolithography and etched $20 \mathrm{~nm}$ using BHF solution. The resist mask is removed and $3 \mu \mathrm{m}$ thick $\mathrm{SiO}_{2}$ layer with refractive index of 1.47 is PECVD-deposited, playing the role of top cladding. Finally, the waveguide structures are diced with precision saw, yielding optical quality of the coupling input/output facets.

For this waveguide, the loss characterization was performed using a special test sample, as shown in Figure 12. The method consists on measuring the intensity of the propagated light in a succession of 30 curved waveguides of different length. The length of curved portion of all waveguides length is identical, only the length of the straight portion of waveguides increases from the bottom to the top of the structure.

Assuming that the loss in the bent waveguides and the coupling efficiency of all waveguides are similar, we can estimate the attenuation:

$$
\alpha_{n}=\frac{10 \log _{10}\left(I_{0} / I_{n}\right)}{\Delta z_{n}}(\mathrm{~dB} / \mathrm{cm})
$$

where $I_{0} / I_{n}$ is the relative output intensity ratio and $\Delta z_{n}$ the difference of optical path. By linear interpolation (see Figure 13), we obtain an average loss of $0.89 \mathrm{~dB} / \mathrm{cm}$ for TE polarisation.

The main advantage of this method is the delivery of an average value of loss across the large number of waveguides, the 


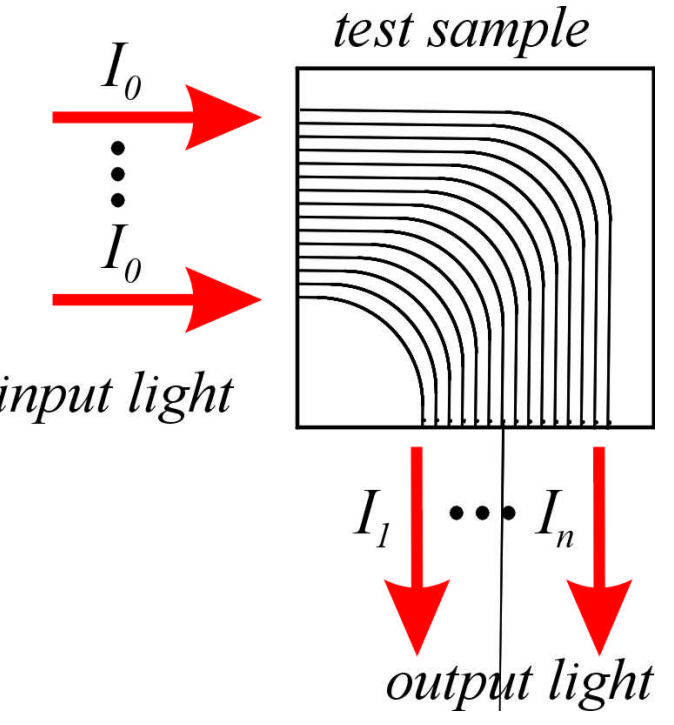

FIG. 12 Waveguide structure used as test sample to measure the optical loss

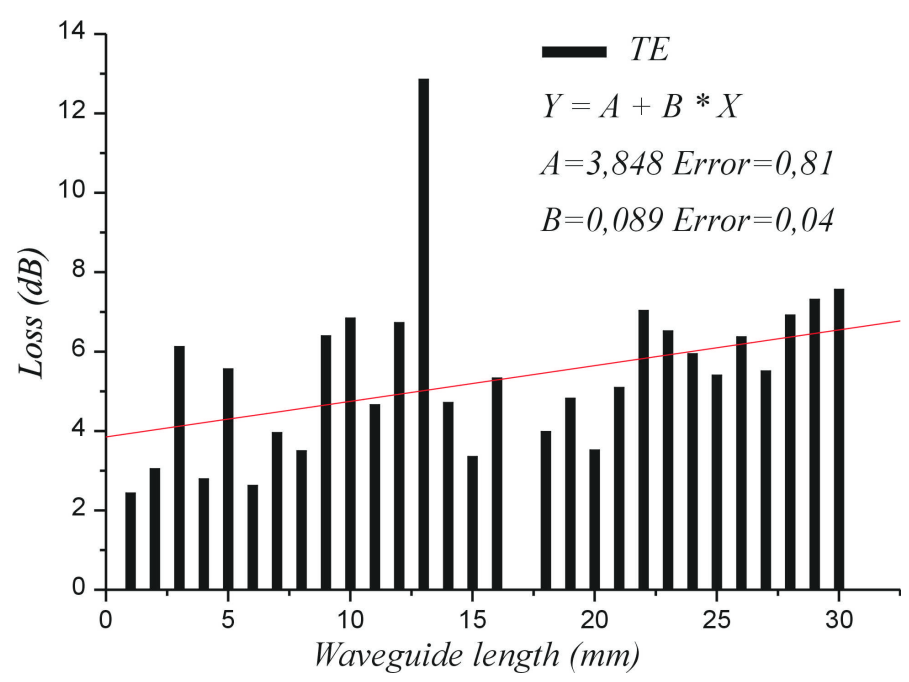

FIG. 13 Experimental data of waveguide attenuation (TE polarisation).

measurements being based on only straight section of waveguides with minimisation of coupling effects.

\subsection{Micromachined platform for self-aligned fiber-to-waveguide coupling}

A simple micromachined solution is proposed for coupling light from fiber to channel waveguide. This is based on the etching of the waveguide substrate with the manufacturing of self-aligned U-grooves, supporting fibers in the same substrate as the waveguide substrate. This approach permits the passive alignment from fiber to waveguide, using vertically the bottom of the U-groove and horizontally the rib structures of the waveguide. The rib of the waveguide and the U-groove are both defined in a single photolithography step. After the deposition of $10 \mathrm{~nm}$ thick layer of $\mathrm{Cr}$, the waveguide and $\mathrm{U}$ groove lateral marks are patterned by photolithography and etched in a standard $\mathrm{Cr}$ etch solution. Without removing the resist, the waveguide is patterned by BHF wet etching and then the resist is removed. The U-groove area is then protected and $\mathrm{Cr}$ mask is etched from the waveguide top surface. After resist cleaning, waveguide deposition process is finished by deposition of a $3 \mu \mathrm{m} \mathrm{SiO}$ top cladding layer. Thus, we obtain two buried $\mathrm{Cr}$ marks, aligned with the input of waveguide rib, as shown in Figure 14a. The waveguide layers are etched by standard ICP-RIE (inductive coupled plasma reactive ion etching) process using larger opening that requires no critical alignment, as shown in Figure 14b. When the $\mathrm{Cr}$ is reached, the $\mathrm{Cr}$ mask acts like as an etch stop and defines self-aligned U-groove lateral limits, as shown in Figure 14c. Silicon etch is completed in a deep RIE (DRIE) process through $\mathrm{Cr} / \mathrm{SiO}_{2}$ mask, providing an excellent selectivity.

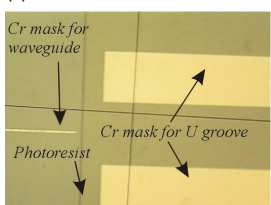

(b)

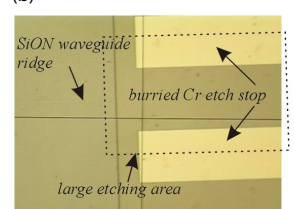

(c)

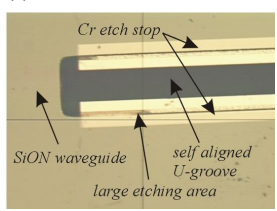

FIG. 14 Self-aligned technology for fiber-to-waveguide coupling: (a) $\mathrm{Cr}$ buried layers aligned on rib mask; (b) same structure after RIE etch of waveguide; and (c) double $\mathrm{Cr}$ mask playing the role of etch mask for self-alignment.

The last step of process consists on a partial dicing and polishing the coupling interface using a high precision dicing saw with resinöid blades. A $100 \mu \mathrm{m}$ deep transverse channel is diced between the output of U-groove and input facet of the waveguide. The dicing operation reduces the roughness of the waveguide input facet, improving the quality of the coupling interface. Figure 15 shows the light coupled from the self-aligned fiber to the core of $\mathrm{SiO}_{x} \mathrm{~N}_{y}$ waveguide. The pre-

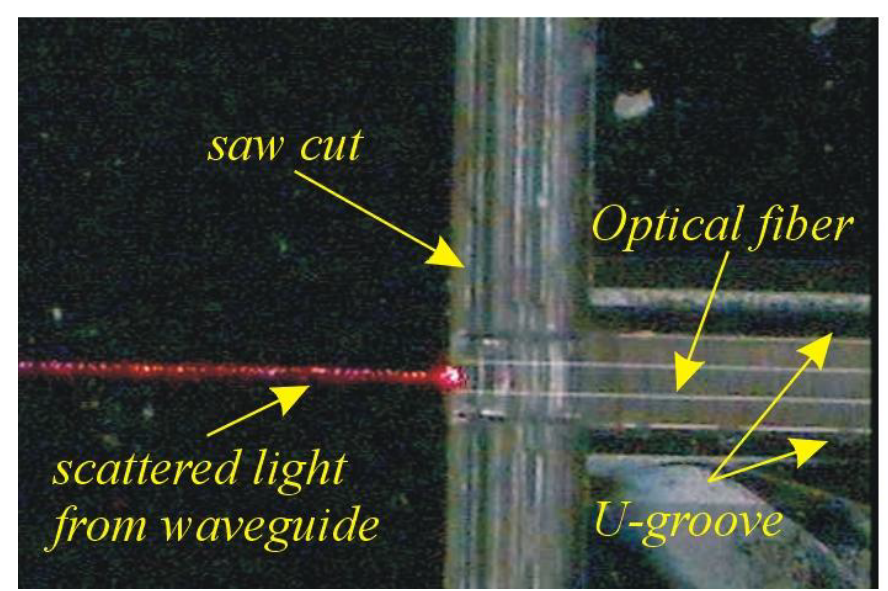

FIG. 15 Light coupling from the self-aligned fiber to the $\mathrm{SiO}_{\mathrm{x}} \mathrm{N}_{\mathrm{y}}$ waveguide.

cision lateral alignment is $0.25 \mu \mathrm{m}$, depending mainly on the under etch of the $\mathrm{Cr}$ mask. The vertical precision of alignment is $1 \mu \mathrm{m}$, depending strongly on the DRIE process control. The fiber extremities are immobilised by gluing with a low stress epoxy glye. 


\section{EXPERIMENT}

Figure 16 compares the optical mode of MZI waveguide with the output mode of the fiber, demonstrating a good matching for the coupling from fiber to waveguide. In agreement with the simulations (Section 4.2), the coupling efficiency of about $3 \mathrm{~dB}$ per facet of MZI is experimentally confirmed. The
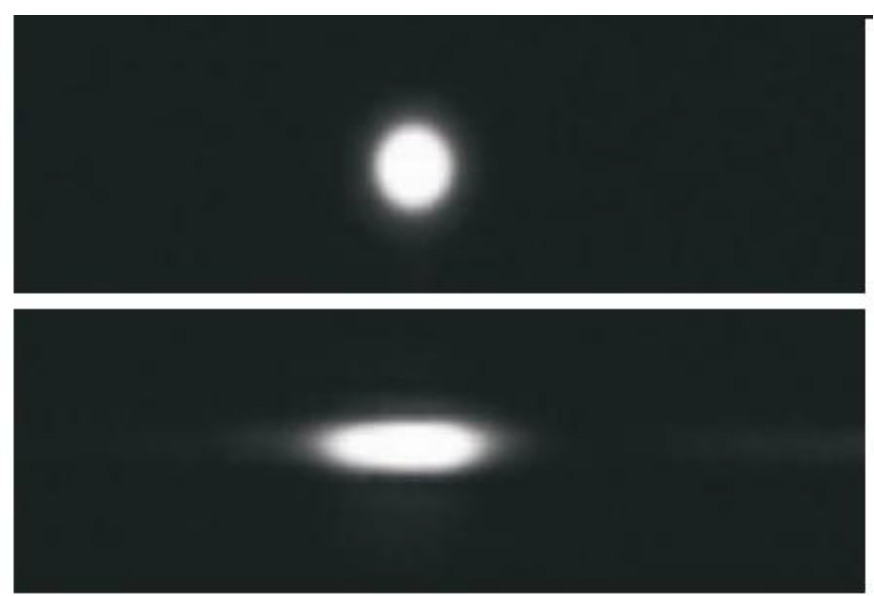

FIG. 16 Comparison of fiber optic input mode (top) with waveguide output mode (bottom).

experimental set-up consists on an active alignment technique using piezoelectrically driven stages for positioning the optical fibers. The light source is a pigtailed laser diode emitting at $670 \mathrm{~nm}$. The single mode fibers are used for coupling the light into the core of the waveguide. The energy of waveguide mode is collected by CCD camera and then compared with the output of optical fiber. Using the Gaussian approximation, the overlap between the intensity of the modal fields is defined as:

$$
\eta_{f g}=\frac{4 a^{2} x y}{\left(a^{2}+x^{2}\right)\left(a^{2}+y^{2}\right)}
$$

where $x$ and $y$ represent the energy following the horizontal direction and vertical direction of the waist, and $a$ represents the energy of symmetrical mode of optical fiber (measured at $1 / e$ of the maximum).

The resulting data are given in Table 3 for a set of 9 waveguides.

\begin{tabular}{|c|c|c|c|c|}
\hline & $x(\mu \mathrm{m})$ & $y(\mu \mathrm{m})$ & $a(\mu \mathrm{m})$ & $\eta(\%)$ \\
\hline 1 & 7,4 & 2,1 & 3,7 & 69,2 \\
\hline 2 & 8,3 & 2,2 & 3,7 & 65,5 \\
\hline 3 & 6,2 & 1,9 & 3,7 & 72,6 \\
\hline 4 & 7,4 & 2,1 & 3,7 & 69,2 \\
\hline 5 & 6,2 & 2,1 & 3,7 & 76,1 \\
\hline 6 & 6,7 & 1,7 & 3,7 & 64,0 \\
\hline 7 & 6,5 & 2,3 & 3,7 & 77,3 \\
\hline 8 & 7,0 & 2,0 & 3,7 & 70,1 \\
\hline 9 & 6,2 & 2,3 & 3,7 & 78,8 \\
\hline
\end{tabular}

TABLE 3 Lateral and horizontal overlaps between fiber and waveguide output and efficiency of coupling.
The measured overlap $\eta_{f g}$ varies between $62 \%$ and $78 \%$ and is slightly greater than expected one. The deviation could be explained by a systematic error induced by the Gaussian approximation and due to end face scattering of the waveguide. This justifies the excessive dispersion of data.

A MZI with one of arms, crossing the center of a $4 \times 4 \mathrm{~mm}^{2}$ silicon membrane, is fabricated. Figure 17 shows a top view of the propagation along the MZI. We used this MZI config-

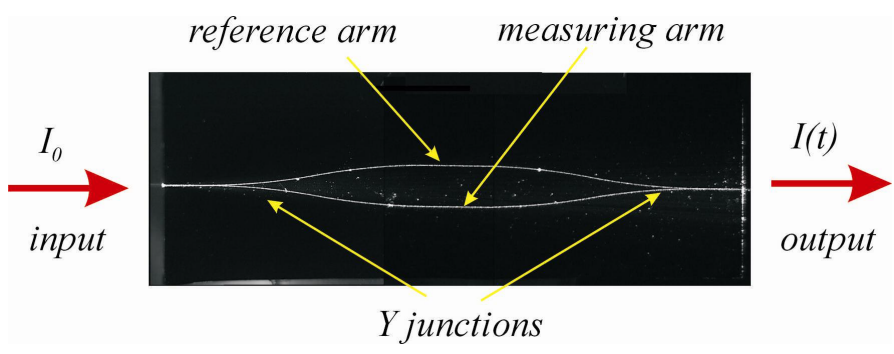

FIG. 17 Top view of the light scattered during propagation along MZI.

uration as an optical pressure sensor. A pressure differential across the membrane causes deflections, which induce strains in the membrane. This mechanical effect is modulating the optical read-out of MZI, producing a shift of interference fringes, as shown in Figure 18. We conclude that the fringe contrast

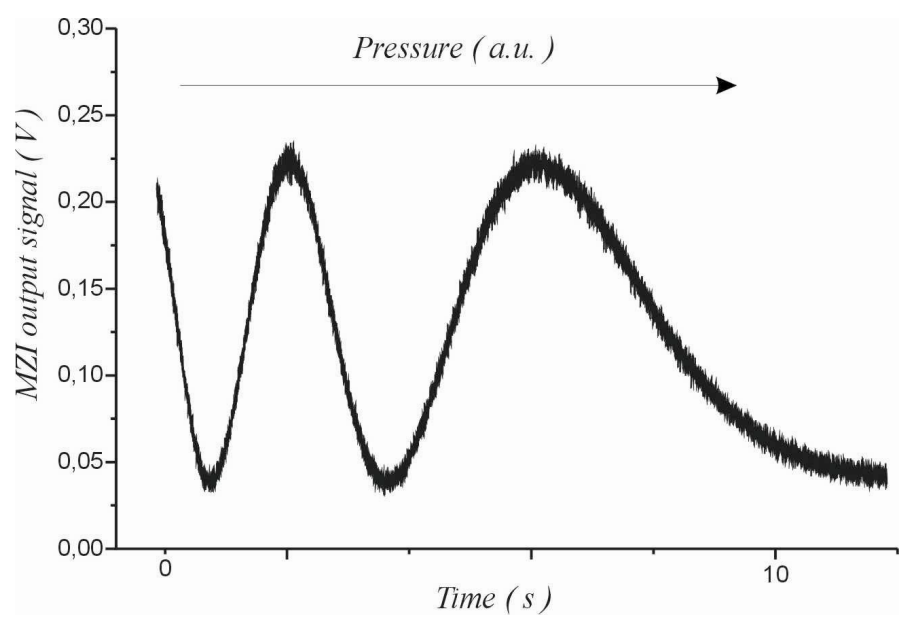

FIG. $18 \mathrm{MZI}$ output signal vs. applied pressure.

of the MZI is over $85 \%$, while the total optical loss is in the range of $18 \mathrm{~dB}$. This value is higher than the calculated one because of additional losses caused by the roughness of the layers and the imperfections of photolithography. Optical loss can be minimized by polishing the substrate surface using the CMP (chemical mechanical planarisation) machine before the core deposition as well as by use of high resolution photolithography masks.

\section{CONCLUSIONS}

We demonstrated that optical sensors using planar silicon oxynitride waveguides can be fabricated reliably using conventional chip fabrication techniques. The observation that PECVD SiO $\mathrm{N}_{y}$ film can be deposited with low compressive 
stress while having good control of refractive index makes these layers attractive candidates for applications as core layer and silicon oxide as cladding layers of buried channel waveguide. Optimization of such optical waveguide is carried out using numerical calculation, minimizing loss propagation and to provide good coupling matching with single mode optical fibers. Using this approach, conventional passive optical components such as Mach Zehnder interferometer integrated on top of deformable membranes can be manufactured in a more compact way than using standard silica-on-silicon waveguide techniques. Combining the Integrated Optics with silicon micromachining enables high precision fabrication of optomechanical sensors.

\section{References}

[1] C. Gorecki, "Optical waveguides and silicon-based micromachined architectures" in MEMS and MOEMS - Technology and Applications, (SPIE Press, Bellingham, 2000).

[2] M. Tabib-Azar, G. Beheim, "Modern trends in microstructures and integrated optics for communication, sensing, and actuation" 0pt. Eng. 36, 1307 (1997).

[3] K. E. Burcham, G. N. De Brabander, J. T. Boyd, "Micromachined silicon cantilever beam accelerometer incorporating an integrated optical waveguide" Proc. SPIE 1793, 12 (1992).

[4] E. Bonnotte, C. Corecki, H. Toshiyoshi, H. Kawakatsu, H. Fujita, K. Wörhoff, K. Hashimoto, "Guided wave acoustooptic interaction with phase modulation in a ZnO thin-film transducer on an Sibased integrated Mach-Zehnder interferometer" J. Lightwave Technol. 17, 35 (1999).

[5] W. Huang, R. M. Shubair, A. Nathan, and Y. L. Chow, "The modal characteristics of ARROW structures" J. Lightwave Technol. 10, 1015 (1992).

[6] K. Fischer, J Muller, R Hoffmann, F. Wasse and D. Salle, "Elastooptical properties of SiON layers in an integrated optical interferometer used as a pressure sensor" J. of Lightwave Technology 12163 (1994).

[7] M. Ohkawa, M. Izutsu, and T. Sueta, "Integrated optic pressure sensor on silicon substrate" Appl. Optics 28, 5153 (1989).

[8] C. H. Henry, R. F. Kazarinov, H. J. Lee, K. J. Orlowsky, L. E. Katz, "Low loss $\mathrm{Si}_{3} \mathrm{~N}_{4}-\mathrm{SiO}_{2}$ optical waveguides on Si" Appl. Optics 26, 2621 (1987).

[9] W. Gleine, J. Müller, “Low-pressure chemical vapor deposition silicon_oxinitride films for integrated optics" Appl. Optics 31, 2036 (1992).

[10] M. Kawachi, "Silica waveguides on silicon and their application to integrated-optic components" Opt. Quant. Electron. 22, 391 (1990).
[11] S. Valette, S. Renard, J.P. Jadot, P.Guidon, C. Erbeia, "Silicon-based integrated optics technology for optical sensor applications" Sensor. Actuator. A21-A23, 1087 (1990).

[12] H. Bezzaoui, E. Voges, "Integrated optics combined with micromechanics on silicon" Sensor. Actuator. A29, 219 (1991).

[13] C. Gorecki, F. Chollet, E. Bonnotte, H. Kawakatsu, "Silicon-based integrated interferometer

with phase modulation driven by acoustic surface waves" 0 pt. Lett. 22, 1784 (1997).

[14] S. M. Sze, VLSI Technology (McGraw-Hill, New York, 1988).

[15] L. Nieradko, C. Gorecki, M. Józwik, A. Sabac, R. Hoffmann, A. Bertz, "Fabrication and optical packaging of an integrated Mach-Zehnder interferometer on top of a moveable micromirror" J. Microlith. Microfab. 5, 023009/1 (2006).

[16] C. Gorecki, "Association of MEMS technology with Integrated Optics: demonstration of active membrane in-situ read-out by monolithic integration of silicon-based Mach Zehnder interferometer" Optica Pura y Applicada 38, 65 (2005).

[17] K. Wörhoff, A. Driessen, P. V. Lambeck, L. T. H. Hilderink, P. W. C. Linders, Th. J. A. Popma "Plasma Enhanced Chemical Vapor Deposition Silicon 0xynitride for Application in Integrated 0ptics" Sensor. Actuator. 74, 9-12 (1999).

[18] R. Germann, H.W.M. Salemink, R. Beyeler, G.L. Bona, F. Horst, I. Massarek and B.J. Offrein, "Silicon oxynitride layers for optical waveguide applications" J. Electrochemical Soc. 147, 2237 (1999).

[19] W. A. Lanford, and M.J. Rand, "The hydrogen content of plasmadeposited silicon nitride" J. Appl. Phys. 49, 2473 (1978).

[20] R. Chow, and R. S. Rosler, "Hydrogen content of a variety of plasma-deposited silicon nitrides" J. Appl. Phys. 53, 5630 (1982).

[21] M. Jozwik, C. Gorecki, A. Sabac, P. Delobelle, and M. Kujawinska "Evaluation of micromechanical properties of buckled SiOxNy loaded membranes combining the Twyman-Green interferometry with nanoindentation and point-wise deflection technique" opt. Laser. Eng. 41/5, 703 (2003).

[22] C. Gorecki, A. Sabac, M. Józwik, S.S. Lee, "Characterisation of internal stress of silicon oxinitride thin films fabricated by plasmaenhanced chemical vapour deposition: applications in Integrated Optics" Proc. SPIE 4596, (2001).

[23] M. Józwik, P. Delobelle, C. Gorecki, A. Sabac, L. Nieradko, C. Meunier, F. Munnik, "Optomechanical characterisation of compressively prestressed silicon oxynitride films deposited by plasmaenhanced chemical vapour deposition on silicon membranes" Thin Solid Films 468, 84 (2004).

[24] C. M. M. Denisse, K. Z. Troost, J. B. Oude Elferink, F. H. P. M. Habraken, W. F. van der Weg, and M. Hendriks "Plasma-enhanced growth and composition of silicon oxynitride films" J. Appl. Phys. 60, 2536 (1986). 